\title{
The effects of genotype and infant weight on adult plasma levels of fibrinogen, factor VII, and LDL cholesterol are additive
}

\author{
Jan A Henry, Manjeet Bolla, Clive Osmond, Caroline Fall, David J P Barker, \\ Steve E Humphries
}

\begin{abstract}
High circulating levels of cholesterol, particularly low density lipoprotein (LDL) cholesterol and the clotting factors fibrinogen and factor VII, are associated with increased risk of myocardial infarction. Variations in the plasma levels of these factors are determined in part by polymorphisms in the genes concerned and also by weight at 1 year (infant weight). We have looked at the possibility of interactions between these genetic factors and infant weight in a sample of 290 men and 192 women from Hertfordshire using the $\beta$-fibrinogen $G / A^{-455}$, factor VII R353Q, and ApoE polymorphisms. The rare allele frequencies of the three polymorphisms were 0.19 for $\beta$-fibrinogen, 0.10 for factor VII, and 0.07 and 0.13 for the 2 and 4 alleles of ApoE, and these frequencies were not different in subjects of different infant weight. In this sample, the polymorphisms showed the expected effects on plasma levels of fibrinogen, factor VII, and LDL cholesterol. The $A^{-455}$ allele was associated with higher fibrinogen levels but the effect was only statistically significant in women $(p=0.003)$. The $R 353$ allele was associated with higher factor VII activity in both men and women
\end{abstract}

Keywords: fibrinogen; factor VII; ApoE polymorphisms; infant weight

While the effects of both genetic and environmental influences on risk of coronary heart disease are well known individually, the extent to which they interact has not been characterised. Raised plasma concentrations of fibrinogen, factor VII, and total cholesterol are associated with increased risk of coronary heart disease in men. ${ }^{1}$ They predispose to thrombosis and contribute to the development and progression of atheroma.

Recently, coronary heart disease and its risk factors, hypertension, non-insulin dependent diabetes, and abnormalities in lipid metabolism and blood coagulation, have been shown to be associated with small size at birth and low weight gain during infancy. ${ }^{2-4}$ These associations are independent of adult lifestyle, including smoking, obesity, and social class, and have led to the conclusion that the disease is "programmed" in utero. The "fetal origins hypothesis" proposes that adaptations made by the fetus in response to undernutrition lead to persisting changes in metabolism and organ structure. There is experimental support for this hypothesis, since if pregnant animals are undernourished their offspring show permanent changes, including raised blood pressure and altered glucose-insulin and lipid metabolism..$^{5-7}$

The first direct evidence that coronary heart disease was associated with low growth rates in utero and during infancy came from studies of 16000 men and women who were born in the county of Hertfordshire between 1911 and 1930 and were traced from birth to the present day. ${ }^{28}$ Death rates from coronary heart disease fell progressively between those who weighed less than 5.5 pounds $(2500 \mathrm{~g})$ at birth and those who were more than 9.5 pounds (4310 g). In men, but not women, there was also a strong association with low weight at 1 year of age. A series of studies examined the prevalence of coronary risk factors in relation to early weight. Among men, plasma fibrinogen and factor VII concentrations fell with increasing weight at 1 year (infant weight). ${ }^{9}$ There were no similar associations in women. ${ }^{10}$ It was suggested that the associations in men are a persisting response to impaired liver development during a critical early period. Subsequent studies have provided further evidence for this. ${ }^{11}$ \footnotetext{
( $p<0.0001$ for both). The ApoE2 allele was associated with lower levels of LDL cholesterol $(p=0.03$ in men, $p=0.006$ in women), while the ApoE4 allele was associated with higher levels $(p<0.001$ in men, not significant in women). In this sample of men and women the effect of low infant weight was only associated with significant effects on fibrinogen and LDL cholesterol in the group of men $(p=0.005$ and $p=0.008$ respectively). Compared with the E3E3 subjects, the LDL lowering effect of the E2 allele and the raising effect of the E4 allele was greater in those with low infant weight compared with those with high infant weight (low $v$ high infant weight for E2: $12.7 \% v 9.4 \%$; for E4 $12.7 \%$ $v 8.5 \%$ ). Although in this sample the interactive effect did not reach statistical significance, the additive effect of ApoE genotype and low infant weight on determining plasma LDL cholesterol levels, if confirmed, may be of relevance in determining a person's future risk of atherosclerosis.

(F Med Genet 1997;34:553-558)

Division of
Cardiovascular
Genetics, Department
of Medicine, UCL
Medical School, Rayne
Institute, University
Street, London WC1E
6JJ, UK
J A Henry
M Bolla
S E Humphries
MRC Environmental
Epidemiology Unit,
University of
Southampton,
Southampton General
Hospital,
Southampton SO16
6YD, UK
C Osmond
C Fall
D J P Barker
Correspondence to:
Ms Henry.
Received 29 November 1996
Revised version accepted for
pubation publication 25 February 1997

Division of
Cardiovascular
Genetics, Department
of Medicine, UCL
Medical School, Rayne
Institute, University
Street, London WC1E
6JJ, UK
J A Henry
M Bolla
S E Humphries
MRC Environmental
Epidemiology Unit,
University of
Southampton,
Southampton General
Hospital,
Southampton SO16
6YD, UK
C Osmond
C Fall
D J P Barker
Correspondence to:
Ms Henry.
Received 29 November 1996
Revised version accepted for
pubation

Division of
Cardiovascular
Genetics, Department
of Medicine, UCL
Medical School, Rayne
Institute, University
Street, London WC1E
6JJ, UK
J A Henry
M Bolla
S E Humphries
MRC Environmental
Epidemiology Unit,
University of
Southampton,
Southampton General
Hospital,
Southampton SO16
6YD, UK
C Osmond
C Fall
D J P Barker
Correspondence to:
Ms Henry.
Received 29 November 1996
Revised version accepted for
pubation

997
} 
Table 1 General characteristics (mean [SD]) * the Hertfordshire sample. Confidence intervals (95\%) are given for the allele frequencies

\begin{tabular}{|c|c|c|}
\hline & Men & Women \\
\hline Number & 290 & 192 \\
\hline Age (y) & $64.1[3.1] 290$ & $64.4[2.8] 191$ \\
\hline Height $(\mathrm{cm})$ & $172.3[6.4] 290$ & $160.2[5.8] 190$ \\
\hline Weight (kg) & $79.2[11.5] 290$ & $69.0[11.5] 191$ \\
\hline BMI $\left(\mathrm{kg} / \mathrm{m}^{2}\right)$ & $26.7[3.4] 290$ & $26.9[4.3] 190$ \\
\hline Fibrinogen ${ }^{\star}(\mathrm{mg} / \mathrm{dl})$ & $300[1.20] 289$ & $292[1.18] 177$ \\
\hline Factor VII^ (\% activity) & $109[1.28] 289$ & $133[1.24] 173$ \\
\hline Average chol $(\mathrm{mmol} / \mathrm{l})$ & $6.60[1.1] 290$ & $7.17[1.3] 191$ \\
\hline LDL cholesterol $(\mathrm{mmol} / \mathrm{l})$ & $4.73[1.1] 269$ & $5.08[1.2] 185$ \\
\hline \multicolumn{3}{|l|}{ Rare allele frequency: } \\
\hline$\beta$-fibrinogen $\left(A^{-455}\right)$ & $0.20(0.16-0.23)$ & $0.18(0.14-0.22)$ \\
\hline Factor VII (Q353) & $0.11(0.09-0.14)$ & $0.09(0.06-0.12)$ \\
\hline \multicolumn{3}{|l|}{ ApoE: } \\
\hline 2 allele & $0.06(0.04-0.08)$ & $0.08(0.05-0.11)$ \\
\hline 4 allele & $0.14(0.11-0.17)$ & $0.11(0.08-0.14)$ \\
\hline
\end{tabular}

* Where the analysis was carried out on log transformed values the geometric SDs (GSDs) are presented. These are equivalent to the geometric means.

Genetic variation also determines differences in the plasma levels of proteins such as fibrinogen and factor VII, and lipids such as cholesterol. The molecular or cellular processes that result in "programming" of gene expression are unknown but a better understanding of these functions would be valuable in determining risk profiles for people. We therefore decided to look at fibrinogen, factor VII, and apolipoprotein E genotypes (fig 1) and early growth data in the Hertfordshire sample to see to what extent the variability in plasma concentrations in adult life was the result of interactive or additive effects of genotype and early growth given by infant weight.

Fibrinogen is a liver secreted zymogen converted to fibrin in the final common pathway of blood coagulation. A polymorphism 455 bases upstream of the transcriptional start site of the gene encoding the $\beta$-fibrinogen chain shows a G/A transition which has shown an association with plasma fibrinogen levels in several studies. ${ }^{12-15} \mathrm{Ho}$ mozygotes for the rare $\mathrm{A}^{-455}$ allele have been

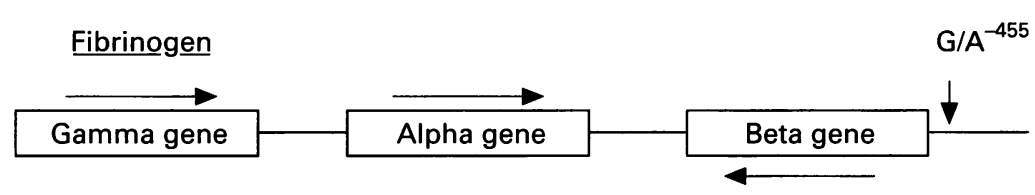

\begin{tabular}{|c|c|c|}
\hline Factor VII & & $\mathrm{CGG} \longrightarrow \operatorname{Arg}_{353}$ \\
\hline & Factor VII coding & \\
\hline
\end{tabular}

\begin{tabular}{ll} 
ApoE & $\begin{array}{l}\text { TGC TGC } \longrightarrow \text { ApoE2 } \\
\text { TGC CGC } \\
\text { CGC CGC } \longrightarrow \text { ApoE3 }\end{array}$ \\
\cline { 2 - 2 } & ApoE coding 112158 \\
\hline
\end{tabular}

Figure 1 Schematic representations of the three gene loci, showing the location of polymorphisms used in this study. Rectangles represent transcribed regions of the gene. For the fibrinogen gene cluster the direction of transcription is shown by an arrow and the location of the G/A change in the beta promoter indicated. For factor VII the sequence of the codon for amino acid 353 is shown, indicating the $G / A$ change that results in the Arg-Gln substitution. For ApoE the sequence of the codons for amino acids 112 and 158 are shown, indicating the C/T changes that result in the Cys-Arg substitution at residue 112 in ApoE4 and the Arg-Cys substitution at residue 158 for ApoE2. shown to have higher levels of plasma fibrinogen than heterozygotes, having levels intermediate to $\mathrm{G}^{-455}$ homozygotes, who have the lowest levels.

Factor VII is also secreted from the liver and acts as part of the extrinsic coagulation pathway. The factor VII polymorphism causes an arginine to glutamine amino acid change at residue 353 (R353Q). ${ }^{16}{ }^{17}$ The common $\mathrm{R} 353$ allele is associated with significantly higher factor VIIc levels in several sample groups. ${ }^{18-21}$

Apolipoprotein $\mathrm{E}$ is a protein of 229 residues important in lipoprotein metabolism. ${ }^{22}$ There are three isoforms E2, E3, and E4 encoded by alleles $\varepsilon 2, \varepsilon 3$, and $\varepsilon 4$ respectively, which differ by amino acid residues at positions 112 and 158. The E2 isoform comprises cysteine residues at both positions, $\mathrm{E} 4$ has two arginine residues, and $\mathrm{E} 3$, the most common form, has Cys at position 112 and Arg at 158. The E4 allele has been associated with coronary artery disease and raised levels of plasma lipids. ${ }^{22-25}$

\section{Materials and methods}

PATIENT RESOURCES

As previously described, all births in Hertfordshire from 1911 onwards were notified by the attending midwife. ${ }^{2}$ Health visitors saw the babies periodically throughout infancy and at 1 year of age the babies were weighed. The NHS central register at Southport was used to trace 10141 boys born during 1911-1930 and 5585 girls born during 1923-1930. Subsamples of men and women still living in Hertfordshire were examined. A subsample of 297 women $^{10}$ and 290 men $^{26}$ from East Hertfordshire has also been described (table 1). Two years after this study the women were invited to reattend the clinic for further measurements and 193 agreed to do so. Plasma fibrinogen, factor VII, and LDL cholesterol measurements were available from 175 women and all 290 men. Assays for plasma fibrinogen, factor VII coagulant, and LDL cholesterol levels were determined as reported previously for this sample. ${ }^{910}$

PREPARATION OF DNA FROM BLOOD SAMPLES DNA was extracted from whole blood using a Triton X-100 lysis method. DNA was then diluted 1:10 in TE buffer and arranged into arrays (Beckman 96 deep well titre plates) for multichannel pipetting into 96 well microtitre plates for DNA amplification.

GENOTYPING

Fibrinogen, factor VII, and ApoE polymorphisms were identified by restriction enzyme digests of DNA amplified by the polymerase chain reaction (PCR) method, as described previously. ${ }^{12} 1627$

STATISTICAL ANALYSIS

Fibrinogen and factor VII levels were log transformed to normality for the statistical analysis, but are presented as the antilog of the mean and the geometric standard deviation (GSD). Fibrinogen levels were adjusted for age, sex, BMI, and smoking status. In the analyses presented, allowing for age, body mass 
Table 2 The rare allele frequencies of three polymorphisms by thirds of infant weight ( 1 y). Confidence intervals (95\%) are given in parentheses with the frequencies. The number of subjects for each weight category is a mean over all the genotypes. It is within 5 of the number available for each genotype

\begin{tabular}{lllll}
\hline & \multicolumn{2}{l}{ Weight at 1 year $(o z)$} & & \\
\cline { 2 - 4 } Polymorphism & $<336(n=180)$ & $<368(n=147)$ & $>368(n=138)$ & Whole group \\
\hline $\begin{array}{l}\text { G/A }{ }^{-455} \\
\quad(\beta-f i b r i n o g e n)\end{array}$ & $0.18(0.14-0.22)$ & $0.23(0.18-0.28)$ & $0.16(0.11-0.20)$ & $0.19(0.16-0.21)$ \\
FVII (R355Q poly) & $0.10(0.07-0.13)$ & $0.10(0.06-0.13)$ & $0.11(0.07-0.15)$ & $0.10(0.08-0.12)$ \\
ApoE: & & & & \\
$\quad$ 2 allele & $0.07(0.04-0.10)$ & $0.06(0.03-0.09)$ & $0.07(0.04-0.10)$ & $0.07(0.05-0.09)$ \\
$\quad$ allele & $0.11(0.08-0.14)$ & $0.14(0.10-0.18)$ & $0.13(0.09-0.17)$ & $0.13(0.11-0.15)$ \\
\hline
\end{tabular}

Table 3 Plasma fibrinogen levels by $G / A^{-455}$ genotype and infant weight $(A)$ in men, $(B)$ in women

\begin{tabular}{|c|c|c|c|}
\hline \multirow[b]{3}{*}{ Infant weights } & \multicolumn{3}{|c|}{ *Plasma fibrinogen ( $\mathrm{mg} / \mathrm{dl}$ ) } \\
\hline & \multicolumn{2}{|l|}{$G / A^{-455}$ genotypes } & \multirow[b]{2}{*}{ Whole group } \\
\hline & $G G$ & $G A \mathscr{E} A A$ & \\
\hline \multicolumn{4}{|l|}{ A } \\
\hline Low $(G S D)$ No $(<344 \mathrm{oz})$ & $308(1.24) 65$ & $308(1.22) 31$ & $308(1.24) 96$ \\
\hline Medium (GSD) No $(<372 \mathrm{oz})$ & $304(1.20) 52$ & $292(1.16) 37$ & $299(1.19) 89$ \\
\hline High (GSD) No $(>372 \mathrm{oz})$ & $281(1.16) 68$ & $299(1.13) 26$ & $286(1.17) 94$ \\
\hline Whole group (GSD) No & $299(1.18) 185$ & $296(1.21) 94$ & $297(1.20) 279$ \\
\hline \multicolumn{4}{|l|}{ B } \\
\hline Low (GSD) No $(<320 \mathrm{oz})$ & $297(1.14) 44$ & $304(1.14) 19$ & $299(1.14) 63$ \\
\hline Medium (GSD) No $(<352 \mathrm{oz})$ & $291(1.18) 33$ & $324(1.17) 24$ & 305 (1.18) 57 \\
\hline High (GSD) No $(>352 \mathrm{oz})$ & $281(1.21) 39$ & $304(1.14) 16$ & $288(1.19) 55$ \\
\hline Whole group (GSD) No & $290(1.18) 103$ & $312(1.16) 59$ & $297(1.17) 175$ \\
\hline
\end{tabular}

* Adjusted for age, sex, BMI, smoking.

Table 4 Factor VIIc activity grouped by genotype and infant weight $(A)$ in men, (B) in women

\begin{tabular}{llll}
\hline & \multicolumn{2}{l}{ Plasma factor VII (\% activity) } & \\
\cline { 2 - 3 } & \multicolumn{2}{l}{ Genotypes } & \\
\cline { 2 - 3 } Infant weights & $R R$ & $R Q \xi Q Q$ & Whole group \\
\hline A & & & \\
Low (GSD) No (<320 oz) & $117(1.23) 80$ & $86(1.20) 16$ & $111(1.27) 96$ \\
Medium (GSD) No (<352 oz) & $117(1.20) 68$ & $87(1.31) 22$ & $109(1.28) 90$ \\
High (GSD) No (>352 oz) & $116(1.26) 74$ & $88(1.27) 23$ & $109(1.30) 97$ \\
Whole group (GSD) No & $117(1.23) 222$ & $87(1.26) 61$ & $110(1.29) 283$ \\
B & $138(1.22) 50$ & $108(1.21) 13$ & $131(1.24) 63$ \\
Low (GSD) No (<320 oz) & $138(1.21) 42$ & $108(1.15) 11$ & $131(1.23) 53$ \\
Medium (GSD) No (<352 oz) & $144(1.21) 50$ & $101(1.20) 6$ & $138(1.24) 56$ \\
High (GSD) No (>352 oz) & $140(1.21) 142$ & $107(1.19) 30$ & $133(1.23) 172$ \\
$\quad$ Whole group (GSD) No & & & \\
\hline
\end{tabular}

Table 5 The ApoE genotype effect on LDL cholesterol levels by infant weight category $(A)$ in men, (B) in women

\begin{tabular}{|c|c|c|c|c|}
\hline \multirow[b]{3}{*}{ Infant weights } & \multicolumn{4}{|c|}{ Plasma LDL levels (mmol/l) } \\
\hline & \multicolumn{3}{|l|}{ Genotypes } & \multirow[b]{2}{*}{ Whole group } \\
\hline & $\begin{array}{l}\text { E2 allele } \\
\text { present }\end{array}$ & $E 3 E 3$ & $\begin{array}{l}\text { E4 allele } \\
\text { present }\end{array}$ & \\
\hline \multicolumn{5}{|l|}{ A } \\
\hline Low (SEM) No (<344 oz) & $4.21(0.4) 11$ & $4.82(0.1) 58$ & $5.43(0.3) 20$ & $4.88(0.1) 89$ \\
\hline Medium (SEM) No $(<372 \mathrm{oz})$ & $3.96(0.6) 5$ & $4.78(0.1) 57$ & $5.04(0.3) 24$ & $4.81(0.1) 86$ \\
\hline High $($ SEM) No (> $372 \mathrm{oz})$ & $4.04(0.3) 8$ & $4.46(0.1) 66$ & $4.84(0.2) 20$ & $4.51(0.1) 94$ \\
\hline Whole group (SEM) No & $4.10(0.2) 24$ & $4.68(0.1) 181$ & $5.10(0.1) 64$ & $4.73(0.1) 269$ \\
\hline \multicolumn{5}{|c|}{ 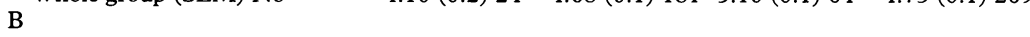 } \\
\hline Low (SEM) No (<344 oz) & $4.03(0.4) 6$ & $5.07(0.2) 47$ & $5.34(0.2) 13$ & $5.03(0.2) 66$ \\
\hline Medium $($ SEM) No $(<372 \mathrm{oz})$ & $5.08(0.5) 6$ & $5.32(0.2) 41$ & $4.95(0.3) 11$ & $5.23(0.2) 58$ \\
\hline High $($ SEM) No $(>372 \mathrm{oz})$ & $4.37(0.3) 10$ & $5.07(0.2) 41$ & $5.38(0.2) 10$ & $5.01(0.1) 61$ \\
\hline Whole group (SEM) No & $4.47(0.2) 22$ & $5.15(0.1) 129$ & $5.23(0.2) 34$ & $5.08(0.1) 185$ \\
\hline
\end{tabular}

index, waist-hip ratio, and smoking had little effect. Allele frequencies were tested using the $\chi^{2}$ test taking $\mathrm{p}=0.05$ as being statistically significant. Thirds of infant weight were calculated separately for men and women, although allele frequencies by infant weight group (table
2) are given for men and women together for simplicity. Infant weight groups are quoted in ounces, as this was the measure initially used (1 $\mathrm{kg}=35.3 \mathrm{oz}$ ). The unequal size of groups found in tables 3, 4, and 5 are the result of frequent reporting of early weight measurements to the nearest pound. In table 2 this is more apparent, owing to the need to derive a compromise grouping for both males and females, since by the age of 1 year the boys are already heavier.

\section{Results}

The general characteristics of the sample have been reported previously ${ }^{10}{ }^{26}$ and are given in table 1 . There was no significant difference in age, BMI, or plasma fibrinogen in the sample between men and women but factor VII and LDL cholesterol were significantly different between genders $(p<0.001$ and $p=0.003)$. The total cholesterol levels observed are in the expected range for men and women of this age. ${ }^{28}$ The rare allele frequencies of the three polymorphisms were 0.19 for $\beta$-fibrinogen, 0.10 for factor VII, and 0.07 and 0.13 for the 2 and 4 alleles of ApoE. Fibrinogen and factor VII genotype distributions were not significantly different from the Hardy-Weinberg equilibrium (table 2); neither was ApoE but only when the sample was divided into men and women. There was no significant difference between rare allele frequencies in thirds of infant weight (table 2) or birth weight (data not shown).

The association between genotypes and plasma traits was examined in men and women separately. For all polymorphisms, because of the low number of subjects homozygous for the rare alleles, comparisons were made between those homozygous for the common allele and those carrying one or more copies of the rare allele. The effect associated with genotype on fibrinogen levels in men was small (table $3 \mathrm{~A}$ ), and in comparison with the common homozygote group (genotype $\mathrm{G} / \mathrm{G}^{-455}$ ), those with one or more $A$ alleles had a non-significant difference of $-1.0 \%(3 \mathrm{mg} / \mathrm{dl})$. In women (table 3B) there was a much larger effect of $+7.6 \%(22 \mathrm{mg} / \mathrm{dl}, \mathrm{p}=0.003)$. Greater differences in plasma fibrinogen across infant weight groups were observed in men than women, with levels $7.7 \%$ higher in the low than the high infant weight groups $(22 \mathrm{mg} / \mathrm{dl}, \mathrm{p}=0.005)$ but only $+3.8 \%$ in women $(11 \mathrm{mg} / \mathrm{dl}$, not significant). Comparing the effect of genotype in the thirds of infant weight, the difference between the fibrinogen levels of the lowest and highest risk groups (as predicted from previous studies, that is, low infant weight and an $A$ allele present versus GG subjects who had high infant weight) is $27 \mathrm{mg} / \mathrm{dl}$ in men and $23 \mathrm{mg} / \mathrm{dl}$ in women, increases of $9.6 \%$ and $8.2 \%$ respectively.

The effects of factor VII genotype and infant weight on factor VII activity were more similar between men and women than for fibrinogen (table 4) although the actual activities were significantly different $(p<0.001)$. Male and female differences in factor VII coagulant activity levels between the common homozygote and subjects with a $Q$ allele were $34.5 \%$ and $30.8 \%$ 


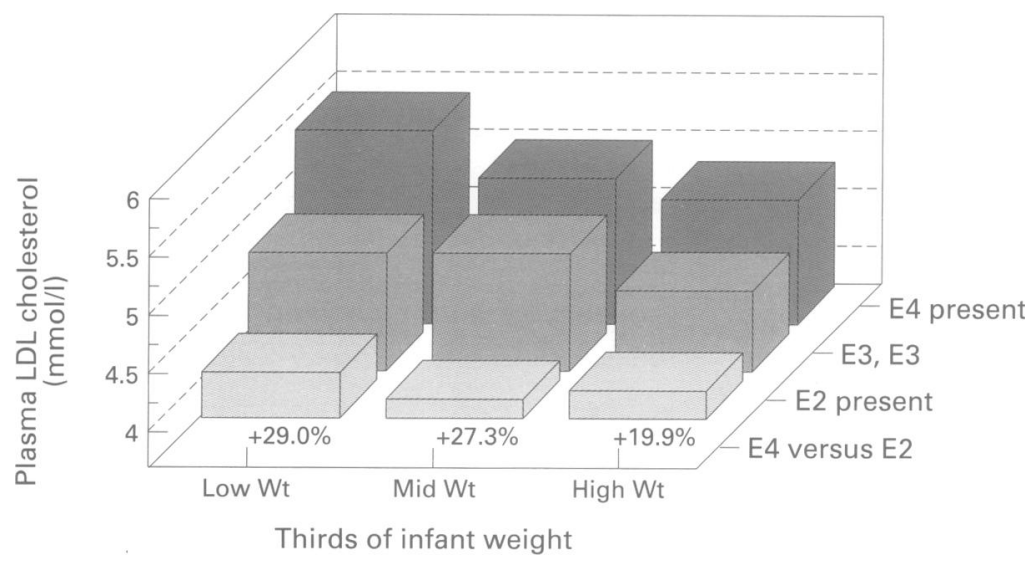

Figure 2 Histogram of plasma LDL cholesterol levels in men in thirds of weight at 1 year ( $<344 \mathrm{oz}, 345-372 \mathrm{oz}$, and $>372 \mathrm{oz}$ ) and divided by ApoE genotype. Data from those with the genotypes ApoE2E2 and ApoE2E3 are combined and those with the genotypes $A$ PoE4E 4 and ApoE3E4 are combined and compared with those with the genotype ApoE3E3.

lower respectively $(p<0.001)$. The highest factor VII activity level in women was found in R353 homozygotes in the high infant weight group. No effect of low infant weight on factor VII was observed in this sample.

The effects of ApoE genotype and infant weight on plasma levels of LDL cholesterol are comparable and significant in men (table $5 \mathrm{~A}$, fig 2). Compared to the E3E3 group the overall lowering effect of the E2 allele in men is $12.4 \%(0.58 \mathrm{mmol} / \mathrm{l}, \mathrm{p}=0.025)$ and the $\mathrm{E} 4$ raising effect is $9.0 \%(0.42 \mathrm{mmol} / \mathrm{l}, \mathrm{p}<0.001)$. The difference between high and low infant weight groups is $+8.2 \% \quad(0.37 \mathrm{mmol} / \mathrm{l}$, $\mathrm{p}=0.008$ ). In women (table $5 \mathrm{~B}$ ) there is a significant lowering effect of the E2 allele on LDL cholesterol levels $(13.2 \%, \mathrm{p}=0.006)$ compared with ApoE3E3 subjects. The raising effect of E4 (versus E3E3) and the effect of low infant weight are $+1.6 \%$ and $+0.4 \%$ respectively. The data for women do not show consistent relationships between LDL cholesterol and genotype or infant weight, which may be because of the power being limited by the smaller numbers involved. However, even in the men, regression analysis failed to show evidence for any statistically significant interactions between infant weight and any of the polymorphisms examined.

The data were also examined with respect to the possible interaction between thirds of birth weight, genotype, and plasma levels of risk factors. As found for infant weight, birth weight was associated with statistically significant effects in men $(p=0.008)$ but not in women, although the $A$ allele raising effect was of similar magnitude in the lowest and highest birth weight groups (data not shown). For both factor VII and LDL cholesterol there was no significant effect associated with birth weight in this sample.

\section{Discussion}

We have analysed a sample of 290 men and 192 women for whom birth weight, infant weight, and lipid and clotting factor data were available, looking at fibrinogen, factor VII, and ApoE genotypes and weight at 1 year (infant weight). A priori we would expect the effect of alleles raising fibrinogen, factor VII, and LDL cholesterol to be additive with the effects of low infant weight rather than interactive. One way in which genotype might interact with low infant weight to predispose to high levels of a risk factor would be if the allele associated with increased levels of the trait were more frequent in infants in the low weight category. Our data show no support for this possibility. Allele frequencies in this sample were similar to those reported previously ${ }^{12} 16^{22}$ and were not different in men or women with different birth weight (data not shown) or infant weight.

A second way genotype and infant weight would show interaction would be if the size of the raising effect associated with an allele was different in infants of different weights. A mechanistic explanation for this would be that changes in expression of the gene had been programmed by in utero nutritional events. A similar phenomenon has been seen in vitro where glucose induced fibronectin overexpression has remained many generations after glucose has been removed from the milieu, the fibronectin gene thought to have been permanently switched on by the initial glucose challenge. ${ }^{29}$

In this small sample of men and women there was an association between infant weight and higher fibrinogen in men $(p=0.005)$, no association between infant weight and factor VII levels in either gender, and an association with LDL cholesterol in men for both $\mathrm{E} 2$ and E4 alleles ( $p=0.008$ for both). The fibrinogen $\mathrm{A}^{-455}$ allele was only associated with a significant raising effect in women $(p=0.003)$ and the factor VII R353 allele was strongly associated with high factor VII activity in both men and women $(\mathrm{p}<0.001)$. The ApoE2 allele was associated with lower LDL cholesterol in men $(p=0.008)$ and women $(\mathrm{p}=0.006)$ and the E4 allele was associated with higher LDL cholesterol in men $(\mathrm{p}=0.001)$.

For factor VII and ApoE, the magnitudes of the genotype associated effects in the whole group of men and women are similar to those reported previously. Those with one or more copies of the factor VII Q353 allele had levels lower by $30 \%$ in men and $33 \%$ in women, similar to the $25-30 \%$ lower levels previously reported in healthy men and women. ${ }^{16-21}$ For ApoE2 compared to the E3E3 group, the lowering effect associated with the ApoE2 genotype is $0.58 \mathrm{mmol} / 1$ in men and $0.68 \mathrm{mmol} / 1$ in women, and the raising effect associated with the ApoE4 genotype is $0.42 \mathrm{mmol} / 1$ in men, but only $0.08 \mathrm{mmol} / \mathrm{l}$ in women. In studies of healthy men and women of this age (64 years), ApoE2 lowering effects in the range 0.62-0.75 $\mathrm{mmol} / \mathrm{l}$ and ApoE4 raising effects in the range $0.03-0.23 \mathrm{mmol} / 1$ have been reported. ${ }^{30} 31$

The analysis is highly suggestive of a biologically important influence, although the molecular mechanism of this genotype and infant weight effect is unclear. Weight at 1 year is a surrogate measure of both poor fetal nutrition leading to low birth weight, and poor infant nutrition leading to poor weight gain after birth. The major function of ApoE is to act as a ligand for the hepatic clearance of triglyceride 
rich lipoproteins of intestinal and hepatic origin, ${ }^{22}$ such clearance being both via the ApoB and ApoE "LDL" receptor and the LDL receptor related protein. ${ }^{32}$ Recently, other receptors have been identified that may also be involved in this process. ${ }^{33}$ If poor fetal or infant nutrition were to result in the permanent "down regulation" of one or more of these key receptors, it might result in permanently slow lipoprotein clearance and thus higher plasma lipid levels. The well known role of the ApoE2/ $\mathrm{E} 3 / \mathrm{E} 4$ genetic isoforms in determining differences in lipid metabolism would then be additive to, and exacerbated by, the hepatic programming of receptor gene expression.

For the fibrinogen promoter genotype, we and others have previously reported in several large healthy samples of middle aged men (mean age 47 years) that those with one or more $\mathrm{A}^{-455}$ alleles have fibrinogen levels between 0.2-0.4 g/l higher. ${ }^{12-15}$ However, in a sample of older men ( $>65$ years) this genotype effect was much smaller ${ }^{34}(<0.1 \mathrm{~g} / \mathrm{l})$ and we speculated that older men with high fibrinogen levels may no longer be in the healthy group. The observations here confirm the lack of an association between the $\mathrm{A}$ allele and higher fibrinogen in older men, though the mechanisms proposed could only be explored by longitudinal studies. By contrast, in the women, the expected association between the A allele and higher fibrinogen levels was seen clearly $(0.22 \mathrm{~g} / 1 \mathrm{higher})$ and was statistically significant. In a sample of healthy men and women (mean age 23 years) we have previously observed the opposite pattern, with the men but not women showing the A allele association with higher fibrinogen, ${ }^{15}$ and we speculated that hormonal effects may explain this difference. In these postmenopausal women it may be that the lack of female hormones may result in a more "young male-like" association between the A allele and higher fibrinogen levels. Although the molecular mechanism of the fibrinogen raising effect associated with the $A$ allele is not fully defined, it is likely to be the result of the sequence change itself (or a nearby sequence change) affecting promoter strength and rates of transcription of the fibrinogen gene and thus the plasma levels of fibrinogen. Hormonally induced effects on the expression of nuclear transcription factors may thus underlie this male/female difference in the pattern of expression and the differences seen between pre- and postmenopausal women.

Several prospective and intervention studies have suggested that a $1 \%$ change in LDL cholesterol is associated with a $2 \%$ change in risk of development of CHD. ${ }^{35}$ Thus, in the whole group of men compared to the E3E3 group, the ApoE2 lowering and ApoE4 raising effect would lower risk by $24.9 \%$ in the E2 men and raise it by $46.6 \%$ in the $\mathrm{E} 4$ men. These effects are clearly exacerbated by the influence of weight at 1 year. Compared with the E3E3 men, where low versus high weight is associated with $8.1 \%$ higher LDL cholesterol $(16.2 \%$ greater risk), the effect of low versus high weight in those with the ApoE4 genotype is $12.2 \%$ LDL cholesterol (24.4\% greater risk) and the weight effect is blunted in those with the ApoE2 genotype $(4.2 \%$, or $8.4 \%$ greater risk). If confirmed in a larger sample, the combination of ApoE genotype and weight at lyear would thus be a useful predictor of LDL cholesterol associated CAD risk.

Jan Henry is funded by Glaxo-Wellcome, Steve Humphries and Manjeet Bolla by the British Heart Foundation, and Clive Osmond, Caroline Fall, and David Barker by the Medical Research Council.

1 Meade TW, Brozovic M, Chakrabarti RR, et al. Haemostatic function and ischaemic heart disease: principal results of the Northwick Park Heart Study. Lancet 1986;ii:533-7.

2 Barker DJP, Winter PD, Osmond C, Margetts B, Simmonds SJ. Weight in infancy and death from ischaemic heart disease. Lancet 1989;ii: $577-80$.

3 Barker DJP, Gluckman PD, Godfrey KM, et al. Fetal nutrition and cardiovascular disease in adult life. Lancet 1993;341:938-41.

4 Barker DJP. Fetal origins of coronary heart disease. BMF 1995;311:171-4.

5 Langley SC, Jackson AA. Increased systolic blood pressure in adult rats induced by fetal exposure to maternal low protein diets. Clin Sci 1994;86:217-22.

6 Snoeck A, Remacle C, Reusens B, Hoet JJ. Effects of a low protein diet during pregnancy on the fetal rat endocrine protein diet during pregnancy on the

7 Hales CN, Desai M, Ozanne SE, Crowther NJ. Fishing in the stream of diabetes: from measuring insulin to the conthe stream of diabetes: from measuring insulin to the con-

8 Osmond C, Barker DJP, Winter PD, Fall CHD, Simmonds SJ. Early growth and death from cardiovascular disease in women. BMF 1993;307:1519-24.

9 Barker DJP, Meade TW, Fall CHD, et al. Relation of fetal and infant growth to plasma fibrinogen and factor VII concentrations in adult life. $B M \mathcal{F}$ 1992;304:148-52.

10 Fall CHD, Osmond C, Barker DJP, et al. Fetal and infant growth and cardiovascular risk factors in women. $B M \mathcal{F}$ 1995;310:428-32.

11 Martyn CN, Meade TW, Osmond C, Barker DJP. Plasma concentrations of fibrinogen and factor VII in adult life and their relation to intrauterine growth. $\mathrm{Br} \mathcal{F}$ Haematol 1995;73:363-7.

12 Thomas A, Lamlum H, Humphries S, Green F. Linkage disequilibrium across the fibrinogen locus as shown by five genetic polymorphisms, $\mathrm{G} / \mathrm{A}^{-455}$ (HaeIII), C/T $\mathrm{T}^{-148}$ (HindIII/ gluI), T/G $\mathrm{G}^{+1689}$ (AvaII), and BclI ( $\beta$-fibrinogen) and TaqI AluI), $\mathrm{T} / \mathrm{G}^{+1689}$ (AvaII), and $B c l \mathrm{I}$ ( $\beta$-fibrinogen) and TaqI
$(\alpha$-fibrinogen), and their detection by PCR. Hum Mutat 1994;3:70-81

13 Heinrich J, Funke H, Rust S, et al. Impact of polymorphisms in the $\alpha$ - and $\beta$-fibrinogen gene on plasma fibrinogen concentrations of coronary heart disease patients. Thromb Res 1995;77:209-15.

14 Scarabin P, Bara L, Ricard S, et al. Genetic variation at the beta-fibrinogen locus in relation to plasma fibrinogen concentrations and risk of myocardial infarction. Arterioscler Thromb 1993;13:886-91.

15 Humphries SE, Ye S, Talmud P, et al. European Atherosclerosis Research Study: genotype at the fibrinogen locus ( $\mathrm{G}-455-\mathrm{A}$ beta-gene) is associated with differences in plasma fibrinogen levels in young men and women from different regions in Europe. Evidence for gender-genotypedifferent regions in Europe. Evidence for gender-genotypeenvironment intera

16 Green F, Kelleher C, Wilkes $\mathrm{H}$, et al. A common genetic polymorphism associated with lower coagulation factor VII levels in healthy individuals. Arterioscler Thromb 1991;11 540-46.

17 Tuddenham EGD, Cooper DN. Factor VII. In: The molecular genetics of haemostasis and its inherited disorders. Oxford: Oxford University Press, 1994:112-21.

18 Lane A, Cruickshank JK, Mitchell J, et al. Genetic and environmental determinants of factor VII coagulant activity in ethnic groups at differing risk of coronary heart disease. Atherosclerosis 1992;94:43-50.

19 Humphries SE, Lane A, Green FR, Cooper J, Miller GJ. Factor VII coagulant activity and antigen levels in healthy men are determined by interaction between factor VII men are determined by interaction between factor VII genotype and plasma trie

20 Meilahn E, Humphries SE, Ferrell R, et al. Genetic determination of coagulation factor VIIc levels among healthy middle-aged women. Thromb Haemostas 1995;73 623-5.

21 Lane A, Scarabin PY, Nicaud V, et al. Factor VII Arg/Gln polymorphism determines factor VII coagulant activity in patients with myocardial infarction (MI) and contro subjects in Belfast and France but is not a strong indicato of MI risk in the ECTIM study. Atherosclerosis 1996;119. 119-27.

22 Davignon J, Gregg RE, Sing CF. Apolipoprotein E polmorphism and atherosclerosis. Arteriosclerosis 1988;8:1-21.

23 Dallongeville J, Lussier-Cacan S, Davignon J. Modulation of plasma triglyceride levels by apoE phenotype: a metaanalysis. F Lipid Res 1992;33:447-54.

24 van-Bockxmeer FM, Mamotte CD. Apolipoprotein epsilon 4 homozygosity in young men with coronary heart disease. Lancet 1992;340:879-80. 
25 Hixson JE, Pathobiological Determinants of Atherosclerosis in Youth (PDAY) Research Group. Apolipoprotein E polymorphisms affect atherosclerosis in young men. Arterioscler Thromb 1991;11:1237-44.

26 Vijayakumar M, Fall CHD, Osmond C, Barker DJP. Birthweight at one year and left ventricular mass in adult life. $B r$ Heart F 1995;73:363-7.

27 Bolla MK, Haddad L, Humphries SE, Winder AF, Day INM. High-throughput method for determination of apolipoprotein $\mathrm{E}$ genotypes with use of restriction digestion poprotein $\mathrm{E}$ genotypes with use of restriction digestion analysis by microtitre array diag Chem 1995;41:1599-604.

28 Tunstall-Pedoe H, Smith WCS, Tavendale R. How-oftenthat-high graphs of serum cholesterol. Findings from the Scottish Heart Health and Scottish MONICA studies. Lancet 1989;i:540-2.

29 Roy S, Sala R, Cagliero E, Lorenzi M. Overexpression of fibronectin induced by diabetes or high glucose: phenomenon with a memory. Proc Natl Acad Sci USA 1990;87:4048.

30 Hanis CL, Hewett-Emmett D, Douglas TC, Schull WT. Lipoprotein and apolipoprotein levels among Mexican-
Americans in Starr County, Texas. Arterioscler Thromb 1991;11:123-9.

31 Katzel LI, Fleg JL, Paidi M, Ragoobarsingh N, Goldberg AP. ApoE4 polymorphism increases the risk for exerciseinduced silent myocardial ischemia in older men. Arterioscler Thromb 1993;13:1495-500.

32 Beisiegel U, Weber W, Bengtsson-Olivecrona G. Lipoprotein lipase enhances the binding of chylomicrons to low density lipoprotein receptor-related protein. Proc Natl Acad Sci USA 1991;88:8342-8.

33 Yamamoto T, Hoshino A, Takahashi S, et al. The role of the very low density lipoprotein receptor in the metabolism of plasma lipoproteins containing apoE. Ann NY Acad Sci 1995;17:217-24.

34 Thomas AE, Kelleher C, Green F, Humphries SE Association of genetic variation at the beta-fibrinogen gene locus and plasma fibrinogen levels: interaction between allele frequency of the G/A-455 polymorphism, age and smoking. Clin Genet 1996;50:184-90.

35 Grundy SM. Cholesterol and coronary heart disease. A new era. $\mathcal{F} A M A$ 1986;256:2849-58. 